\title{
The Development of LISTEN: A Novel Intervention for Loneliness
}

\author{
Laurie A. Theeke, Jennifer A. Mallow \\ Department of Adult Health, School of Nursing, West Virginia University, Morgantown, USA \\ Email: Itheeke@hsc.wvu.edu, jamallow@hsc.wvu.edu
}

Received 28 January 2015; accepted 13 February 2015; published 17 February 2015

Copyright (C) 2015 by authors and Scientific Research Publishing Inc.

This work is licensed under the Creative Commons Attribution International License (CC BY). http://creativecommons.org/licenses/by/4.0/

(c) $\underset{\mathrm{EY}}{\mathrm{i}}$ Open Access

\section{Abstract}

Purpose: The purpose of this paper is to present the development of LISTEN (Loneliness Intervention using Story Theory to Enhance Nursing-sensitive outcomes), a new intervention for loneliness. Methods: LISTEN was developed using the Medical Research Council (MRC) framework for intervention development. Extensive literature review revealed that belonging, relating, placing in community, challenges, and meanings of coping were concepts significant to loneliness. Past interventions were limited but it was determined from a recent meta-analysis that enhanced effectiveness might result from interventions that targeted the poorly adapted cognitive processes of loneliness. These processes include social undesirability, stigma, and negative thoughts about self in relation to others. LISTEN is designed to be delivered in a determined logical sequence of 5 sessions, each focusing on the concepts relevant to loneliness as derived from the literature. For each session, intervention delivery is guided by the concepts from story theory (including intentional dialogue, nurse as listener, examination of self in relation to others and community, synthesizing concerns and patterns, and identifying messages) and the principles of cognitive restructuring (self-assessment of maladaptive cognitions, emotions, and behaviors, identifying challenges of changing, reconceptualization of self, new skill acquisition through group interaction, and identifying patterns of meaning in loneliness). Results: LISTEN is developed and the first randomized trial is complete with a sample of 27 lonely, chronically ill, community dwelling, and older adults. LISTEN was evaluated as feasible to deliver by the study team and acceptable for significantly diminishing loneliness by participants of the LISTEN groups who were compared to attention control groups $(p<0.5)$. Conclusions: LISTEN has the potential to enhance health by diminishing loneliness which could result in improving the long-term negative known sequelae of loneliness. Future longitudinal randomized trials are needed in varied populations to assess long term health and healthcare system benefit of using LISTEN to treat loneliness.

\section{Keywords}

Loneliness, LISTEN, Intervention, Behavioral Health 


\section{Introduction}

Loneliness is a prevalent and significant health problem experienced by over $16 \%$ percent of mid-life and older adults in the US [1]. Loneliness is linked to multiple chronic health conditions including: cardiovascular problems like hypertension [2] and stroke [3], metabolic problems such as obesity [4], metabolic syndrome [5], diabetes [6], and behavioral health problems like anxiety [7] and depression [8]. Recently, loneliness was identified to be an independent predictor of functional decline [9] and mortality [10] in older adults. It is thought that loneliness contributes to negative health through the physiological mechanisms [11] associated with stress and it is therefore conceptualized as biopsychosocial stressor. It has recently been suggested that loneliness be considered formally as a social determinant of health, even in young populations [12]. This is important because it emphasizes the significance of loneliness as a major contributor to health problem akin to other social determinants like poverty or lack of education. Highlighting the significant contribution of loneliness to poor health could elevate the study of as a health priority. The known contribution of loneliness to negative health outcomes makes it imperative that effective interventions be identified.

Loneliness can be perceived throughout the lifespan and is the result of multiple psychological subjectivities interacting on a cognitive level, leading to the perception or conclusion that a deficit exists and loneliness is being experienced. Factors such as life expectations and overall life circumstances can contribute to loneliness but, from a healthcare perspective, it is important that the empirically identified psychosocial, environmental, and behavioral risks of developing loneliness are understood. Older adult populations that experience rurality, poverty, lower educational attainment, and multiple chronic conditions may be at increased risk [1]. High loneliness scores have been reported in samples of at-risk youth [13] or youth in foster care [14] who have not historically had the benefit of a consistent support network. Loneliness can occur in times of life transition and has been documented to be prevalent in college students [4], post-partum women [15], new retirees [16], and those who have been newly widowed [17]. In all of these situations, there is usually an adjustment to a significantly new situation, requiring the person to pursue enhanced understanding of self so that they can establish or re-establish their perception of belonging.

Prior intervention studies for loneliness have focused on enhancing individual development or social integration [18]-[22]. These interventions have included activities like participating in social groups that engage in art, writing, or exercise [23] [24]. Others have attempted to diminish loneliness by encouraging volunteerism [25] but these, too, have demonstrated limited effectiveness and sustainability. Masi, Chen, Hawkley, \& Cacioppo (2011) completed a meta-analysis of interventions for loneliness and suggested that interventions could be more effective if they were designed to target the faulty cognitive processes associated with loneliness [26]. These processes include feelings of social undesirability [27], stigma from loneliness or chronic conditions [28], and negative thoughts about self in relation to others or community [29]. The purpose of this paper is to present LISTEN (Loneliness Intervention using Story Theory to Enhance Nursing sensitive outcomes). LISTEN is a complex intervention designed to be target the poorly adapted cognitive processes associated with loneliness, irrespective of age or population.

\section{Method for Intervention Development}

\subsection{The MRC Framework for Complex Intervention Development}

The overall process of intervention development was guided by the Medical Research Council (MRC) framework for developing complex interventions [30]. The MRC framework was originally introduced in the year 2000 as a recommended method for developing complex interventions [31]. The development of the framework stemmed out of the need to evaluate interventions that include multiple interrelated components. Guidance on the MRC method was updated in 2013 [32]. A complex interventions is defined as an intervention that has: interacting components within both experimental and control groups, multiple difficult behaviors required by those who deliver and receive the intervention, multiple groups targeted by the intervention, variance in outcomes, and/or flexibility in tailoring the intervention [32]. The process of developing an intervention using the MRC Framework requires: 1) identifying evidence and acquiring knowledge of a health phenomenon, 2) identifying appropriate theoretical frameworks that could be used to implement an intervention or demonstrate how the intervention could affect change, 3) engage in thought about ways to assess potential effectiveness. 4) Pilot the intervention for feasibility, acceptability and effectiveness in a trial with an appropriate comparator and 5) implement an evaluation plan. 
The first phase of LISTEN development was achieved through extensive literature review on loneliness (Getting to know the health phenomenon) which occurred over a period of 7 years studying the topic. This in-depth study of loneliness which included multiple descriptive trials of loneliness in varied populations revealed that the most effective intervention would potentially be one that addressed dysfunctional thinking associated with loneliness, a conclusion that is congruous with the findings in a meta-analysis of interventions [26]. The study team also identified that it would be important to diminish the meaninglessness [33] or lack of meaningful role [34] that was being described by persons with loneliness.

Preliminary studies conducted included national data set analyses [1] [35] which revealed a prevalence of 19\% loneliness in US adults. This was followed by primary data collection in Appalachia to understand both national and regional concerns with loneliness. Through this work, it was determined that loneliness was related to depression [36], poor quality of life [7], and chronic illness [37]. During preliminary studies, patients who were experiencing loneliness reported that the experience was very stressful situations and that providers didn't listen to what was important to them which created additional psychological distress.

After thoroughly coming to know loneliness as a health phenomenon, the team engaged in the second sought theories that could be used to appropriately to develop and implement an intervention for loneliness. It was determined that both using the principles of cognitive restructuring [38] [39] and concepts from story theory [40] to facilitate cognitive restructuring and finding meaning. The principles of Cognitive Behavioral Therapy (CBT) work toward cognitive reframing and the concepts of story theory focus on the ability of human beings to use story as a way of finding meaning [40]. Therefore, both the principles of CBT and the concepts of story theory were foundational to the development of LISTEN.

\subsection{Principles of Cognitive Restructuring}

Cognitive behavioral therapy (CBT) is an effective therapeutic method for healing psychological misperceptions. CBT has been reported to be effective for diminishing depression for adult samples [41]. Knowing that loneliness is a predictor for depression [42] makes it logical to infer that CBT may be helpful to lonely persons. The core technique of CBT is cognitive restructuring which is also known as reframing. This technique is used in various forms of CBT. The principles of cognitive restructuring include self-assessment of maladaptive cognitions, emotions, and behaviors, identifying challenges of changing, reconceptualization of self, new skill acquisition through group interaction, and identifying patterns of meaning in loneliness. The sessions of LISTEN are sequential to take the participants on a journey from self-awareness to self-in-relation to reconceptualization, and finally, to identifying potential meaning in their experience.

\subsection{Story Theory}

Story theory by Liehr and Smith (2008) is a middle range nursing theory that explains how a story can facilitate healing. Story theory has been used to guide other interventions that have resulted in improved health outcomes [43]. There are three concepts identified as interrelated in story theory and they are: 1) "intentional dialogue” 2) “connecting with self-in-relation” and 3) “creating ease” (p. 209) [40]. These concepts were identified as foundational to the delivery of LISTEN in group sessions [40].

\section{The LISTEN Intervention}

The deep exploration of the conceptual, methodological, and empirical literature on loneliness was foundational to the process of developing LISTEN. LISTEN is developed as a 5 session intervention that has been delivered in a small group setting ( 3 - 5 people). The number and length of sessions was modelled after other forms of CBT that have demonstrated effectiveness such as problem-solving therapy [44] [45] which can be delivered in 5 sessions. The content for the talking points for each session was derived from the literature on loneliness.

The first session focuses on perceived belonging as the construct that matters most about loneliness. The need to belong is a basic human need that has been described since 1955 in Maslow's classic book, Toward a Psychology of Being [46]. In the loneliness literature, unmet belonging can be seen as the antecedent of perceived loneliness [47]. In addition, belongingness support has been linked to diminished loneliness [48] and belonging has been identified as significant to avoiding loneliness [49]. During this first session, participants focus on self-assessment, thinking about self over the life course, belonging, and loneliness. This session allows the par- 
ticipants to evaluate their thinking about belonging and how it may relate to their experience of loneliness. It also facilitates the identification of automatic thoughts they may occur when thinking about loneliness and how these may be similar or different from others who are also experiencing loneliness.

The second session focuses on relationships. The participants are invited to explore both historical and current relationships for "relating and not relating" focusing on self-in-relation, an integral concept to story theory [40]. Perception of relationships and individual role in relationships has been demonstrated to be significant to loneliness in varied populations [50]-[52]. Identifying more meaningful and less meaningful relationships guides participants to enhanced awareness about past and current relationships. Overall, this session facilitates a reconnection with self and a thoughtful reflection of self in relation to others and community.

The third session explores patterns of getting out or staying in. There are known reciprocal relationships between loneliness and functional abilities. Loneliness has been linked to both cognitive functional impairment [53]-[55] and physical functional impairment [56]-[58] in various age groups with various disabilities. The inability to physically get out in community independently can limit meaningful experiences and has been linked to higher loneliness scores [9] [59]. During this session, group participants are able to gain exposure to how others get out or stay in while experiencing loneliness. This allows the participants of LISTEN to begin to reconceptualize the significance of getting out to the experience of loneliness in the context of ideas from other persons with loneliness.

Session four focuses on the ups and downs of loneliness including challenges experienced with loneliness. This session is essential for participants so that they can identify the realities of coping with loneliness based on their experience and the experience of others. Participants are encouraged to identify high points, low points and turning points in their experience of loneliness. This helps them to identify critical moments when their thinking about loneliness may have changed.

The fifth session is about life lessons on loneliness. The focus of this session is on meaning in the experience of loneliness and what might work for diminishing loneliness. Participants are encouraged to identify and discuss patterns within the group regarding the experience of loneliness. This process creates some movement toward resolution, another key concept of story theory [40]. During this session, participants may begin to find meaning in experiences of loneliness from multiple perspectives. During this session, participants recap the first four weeks, differentiate being alone from loneliness, and write messages for others about loneliness. The session ends with a discussion about how each participant will employ knowledge gained from participation in LISTEN to alter their experience of loneliness. Figure 1 provides a summary of the intervention with the links to principles of cognitive restructuring and concepts from Story theory.

\section{Discussion}

The use of the MRC framework was essential to the successful development of LISTEN. Both story theory and the principles of cognitive restructuring were necessary to develop an intervention with true potential to diminish loneliness. LISTEN is not designed for a specific age or population specific rather, designed to diminish loneliness as a unique psychological construct. It is possible that LISTEN would need language adapted if used in samples of young children or for those who have difficulty with verbal communication. The session content is reflective of current knowledge of loneliness presented in the health and social science literature. The first randomized trial of LISTEN has been completed and the results have been presented at national nursing conference [60]. Listen was evaluated as feasible and acceptable by the first trial participants who were 27 older adults with moderate to high loneliness scores as measured by the UCLA Loneliness Scale [61]. This population was chosen because they were discovered to have relatively high loneliness scores in a previous study on loneliness [36] LISTEN group participants of the first trial reported diminished loneliness scores 12 weeks after completing the group sessions $(p<0.05)$ when compared to participants of the attention control group. Participants also reported enhanced quality of life as reported on the visual analog scale for quality of life [62], and positive changes in health behaviors such as joining exercise groups, new community groups, and faith groups 12 weeks after intervention.

\section{Future Implications for Nursing Research}

Based on the process outlined in the MRC framework, the study team has outlined the next steps to further evaluate the effectiveness of LISTEN on loneliness in varied populations. Plans include fully disseminating the re- 
sults of the first trial and seeking funding for larger longitudinal trials of LISTEN in multiple populations. In addition, the study team has completed preliminary work on loneliness with stroke survivors [63], college students [4], children [64], and adults with multiple chronic conditions [65] [66]; building a foundation of knowledge for future studies of LISTEN. In order to understand the long-term benefit of diminishing loneliness and the potential impact this could have on the human health experience, future trials are needed.

\section{Acknowledgements}

This project was funded by the Robert Wood Johnson Nurse Faculty Scholars Program. Dr. Theeke thanks Dr. Mary Jane Smith for her ongoing encouragement on the use of Story Theory in research.

\section{References}

[1] Theeke, L.A. (2010) Sociodemographic and Health-Related Risks for Loneliness and Outcome Differences by Loneliness Status in a Sample of U.S. Older Adults. Research in Gerontological Nursing, 3, 113-125. http://dx.doi.org/10.3928/19404921-20091103-99

[2] Hawkley, L.C., Masi, C.M., Berry, J.D. and Cacioppo, J.T. (2006) Loneliness Is a Unique Predictor of Age-Related Differences in Systolic Blood Pressure. Psychology and Aging, 21, 152-164. http://dx.doi.org/10.1037/0882-7974.21.1.152

[3] Theeke, L.A., Horstman, P., Mallow, B., Culp, A.M., Lucke-Wold, A., Domico, J. and Barr, T.L. (2014) Quality of Life and Loneliness in Stroke Survivors Living in Appalachia. Journal of Neuroscience Nursing, 46, E3-E15. http://dx.doi.org/10.1097/JNN.0000000000000097

[4] Smith, M.J., Theeke, L., Culp, S., Clark, K. and Pinto, S. (2014) Psychosocial Variables and Self-Rated Health in Young Adult Obese Women. Applied Nursing Research, 27, 67-71. http://dx.doi.org/10.1016/j.apnr.2013.11.004

[5] Whisman, M.A. (2010) Loneliness and the Metabolic Syndrome in a Population-Based Sample of Middle-Aged and Older Adults. Health Psychology, 29, 4. http://dx.doi.org/10.1037/a0020760

[6] Amato, L., Paolisso, G., Cacciatore, F., Ferrara, N., Canonico, S., Rengo, F. and Varricchio, M. (1996) Non-InsulinDependent Diabetes Mellitus Is Associated with a Greater Prevalence of Depression in the Elderly. The Osservatorio Geriatrico of Campania Region Group. Diabetes \& Metabolism, 22, 314-318.

[7] Theeke, L.A. and Mallow, J. (2013) Loneliness and Quality of Life in Chronically Ill Rural Older Adults. American Journal of Nursing, 113, 28-37. http://dx.doi.org/10.1097/01.NAJ.0000434169.53750.14

[8] Seo, Y., Yates, B., Dizona, P., Laframboise, L. and Norman, J. (2014) Predictors of Cognitive/Affective and Somatic Depression in Heart Failure Patients. Clinical Nursing Research, 23, 259-280. http://dx.doi.org/10.1177/1054773812473476

[9] Perissinotto, C.M., Stijacic Cenzer, I. and Covinsky, K.E. (2012) Loneliness in Older Persons: A Predictor of Functional Decline and Deathloneliness in Older Persons. Archives of Internal Medicine, 172, 1-7.

[10] Luo, Y., Hawkley, L.C., Waite, L.J. and Cacioppo, J.T. (2012) Loneliness, Health, and Mortality in Old Age: A National Longitudinal Study. Social Science Medicine, 74, 907-914. http://dx.doi.org/10.1016/j.socscimed.2011.11.028

[11] Cacioppo, J.T., Hawkley, L.C., Crawford, L.E., Ernst, J.M., Burleson, M.H., Kowalewski, R.B., Malarkey, W.B., Van Cauter, E. and Berntson, G.G. (2002) Loneliness and Health: Potential Mechanisms. Psychosomatic Medicine, 64, 407417. http://dx.doi.org/10.1097/00006842-200205000-00005

[12] Currie, C. (2012) Social Determinants of Health and Well-Being among Young People. World Health Organization, Regional Office for Europe, Copenhagen.

[13] Galanaki, E.P., Polychronopoulou, S.A. and Babalis, T.K. (2008) Loneliness and Social Dissatisfaction among Behaviourally At-Risk Children. School Psychology International, 29, 214-229. http://dx.doi.org/10.1177/0143034308090061

[14] Linares, L.O., Li, M., Shrout, P.E., Brody, G.H. and Pettit, G.S. (2007) Placement Shift, Sibling Relationship Quality, and Child Outcomes in Foster Care: A Controlled Study. Journal of Family Psychology, 21, 736-743. http://dx.doi.org/10.1037/0893-3200.21.4.736

[15] Matthey, S., Morgan, M., Healey, L., Barnett, B., Kavanagh, D.J. and Howie, P. (2002) Postpartum Issues for Expectant Mothers and Fathers. Journal of Obstetric, Gynecologic, \& Neonatal Nursing, 31, 428-435. http://dx.doi.org/10.1111/j.1552-6909.2002.tb00065.x

[16] Bekhet, A.K. and Zauszniewski, J.A. (2012) Mental Health of Elders in Retirement Communities: Is Loneliness a Key Factor? Archives of Psychiatric Nursing, 26, 214-224. http://dx.doi.org/10.1016/j.apnu.2011.09.007

[17] Ben-Zur, H. (2012) Loneliness, Optimism, and Well-Being among Married, Divorced, and Widowed Individuals. The 
Journal of Psychology: Interdisciplinary and Applied, 146, 23-36. http://dx.doi.org/10.1080/00223980.2010.548414

[18] Van den Elzen, A.J. and Fokkema, C.M. (2006) Home Visits to the Elderly in Leiden: An Investigation into the Effect on Loneliness. Tijdschrift Gerontologie en Geriatrie, 37, 142-146.

[19] Fokkema, C.M. and van Tilburg, T.G. (2007) Loneliness Interventions among Older Adults: Sense or Nonsense? Tijdschrift Gerontologie en Geriatrie, 38, 185-203.

[20] Hartke, R.J. and King, R.B. (2003) Telephone Group Intervention for Older Stroke Caregivers. Topics in Stroke Rehabilitation, 9, 65-81.

[21] Martina, C.M. and Stevens, N.L. (2006) Breaking the Cycle of Loneliness? Psychological Effects of a Friendship Enrichment Program for Older Women. Aging \& Mental Health, 10, 467-475. http://dx.doi.org/10.1080/13607860600637893

[22] Shapira, N., Barak, A. and Gal, I. (2007) Promoting Older Adults’ Well-Being through Internet Training and Use. Aging \& Mental Health, 11, 477-484. http://dx.doi.org/10.1080/13607860601086546

[23] Savikko, N., Routasalo, P., Tilvis, R. and Pitkala, K. (2010) Psychosocial Group Rehabilitation for Lonely Older People: Favourable Processes and Mediating Factors of the Intervention Leading to Alleviated Loneliness. International Journal of Older People Nursing, 5, 16-24. http://dx.doi.org/10.1111/j.1748-3743.2009.00191.x

[24] Pitkala, K.H., Routasalo, P., Kautiainen, H., Sintonen, H. and Tilvis, R.S. (2011) Effects of Socially Stimulating Group Intervention on Lonely, Older People’s Cognition: A Randomized, Controlled Trial. The American Journal of Geriatric Psychiatry, 19, 654-663. http://dx.doi.org/10.1097/JGP.0b013e3181f7d8b0

[25] Rook, K.S. and Sorkin, D.H. (2003) Fostering Social Ties through a Volunteer Role: Implications for Older-Adults' Psychological Health. The International Journal of Aging and Human Development, 57, 313-337. http://dx.doi.org/10.2190/NBBN-EU3H-4Q1N-UXHR

[26] Masi, C.M., Chen, H.Y., Hawkley, L.C. and Cacioppo, J.T. (2011) A Meta-Analysis of Interventions to Reduce Loneliness. Personality and Social Psychology Review, 15, 219-266. http://dx.doi.org/10.1177/1088868310377394

[27] Cheng, S.T. (1992) Loneliness-Distress and Physician Utilization in Well-Elderly Females. Journal of Community Psychology, 20, 43-56. http://dx.doi.org/10.1002/1520-6629(199201)20:1<43::AID-JCOP2290200107>3.0.CO;2-3

[28] Grov, C., Golub, S.A., Parsons, J.T., Brennan, M. and Karpiak, S.E. (2010) Loneliness and HIV-Related Stigma Explain Depression among Older HIV-Positive Adults. AIDS Care: Psychological and Socio-Medical Aspects of AIDS/ HIV, 22, 630-639.

[29] Meltzer, H., Bebbington, P., Dennis, M.S., Jenkins, R., McManus, S. and Brugha, T.S. (2013) Feelings of Loneliness among Adults with Mental Disorder. Social Psychiatry and Psychiatric Epidemiology, 48, 5-13.

[30] Craig, P., Dieppe, P., Macintyre, S., Michie, S., Nazareth, I. and Petticrew, M. (2008) Developing and Evaluating Complex Interventions: The New Medical Research Council Guidance. British Medical Journal, 337, a1655.

[31] Campbell, M., Fitzpatrick, R., Haines, A., Kinmonth, A.L., Sandercock, P., Spiegelhalter, D. and Tyrer, P. (2000) Framework for Design and Evaluation of Complex Interventions to Improve Health. British Medical Journal, $321,694$. http://dx.doi.org/10.1136/bmj.321.7262.694

[32] Craig, P., Dieppe, P., Macintyre, S., Michie, S., Nazareth, I. and Petticrew, M. (2013) Developing and Evaluating Complex Interventions: The New Medical Research Council Guidance. International Journal of Nursing Studies, 50, 587-592. http://dx.doi.org/10.1016/j.ijnurstu.2012.09.010

[33] Andersson, L. (1985) Intervention against Loneliness in a Group of Elderly Women: An Impact Evaluation. Social Science \& Medicine, 20, 355-364. http://dx.doi.org/10.1016/0277-9536(85)90010-3

[34] Casey, M.S. and Holmes, C.A. (1995) The Inner Ache: An Experiential Perspective on Loneliness. Nursing Inquiry, 2, 172-179. http://dx.doi.org/10.1111/j.1440-1800.1995.tb00168.x

[35] Theeke, L.A. (2009) Predictors of Loneliness in U.S. Adults over Age Sixty-Five. Archives of Psychiatric Nursing, 23, 387-396. http://dx.doi.org/10.1016/j.apnu.2008.11.002

[36] Theeke, L.A., Goins, R., Moore, J. and Campbell, H. (2012) Loneliness, Depression, Social Support, and Quality of Life in Older Chronically Ill Appalachians. The Journal of Psychology: Interdisciplinary and Applied, 146, 155-171. http://dx.doi.org/10.1080/00223980.2011.609571

[37] Theeke, L.A. and Mallow, J.A. (2013) Loneliness and Quality of Life in Rural Chronically Ill Older Adults. American Journal of Nursing, 113, 28-38. http://dx.doi.org/10.1097/01.NAJ.0000434169.53750.14

[38] Cohen-Mansfield, J. and Parpura-Gill, A. (2007) Loneliness in Older Persons: A Theoretical Model and Empirical Findings. International Psychogeriatrics, 19, 279-294.

[39] Hopps, S.L., Pepin, M. and Boisvert, J.M. (2003) The Effectiveness of Cognitive-Behavioral Group Therapy for Loneliness via Inter-Relay-Chat among People with Physical Disabilities. Psychotherapy, 40, 136-147.

http://dx.doi.org/10.1037/0033-3204.40.1-2.136 
[40] Liehr, P. and Smith, M. (2008) Story Theory. Middle Range Theory for Nursing, 2nd Edition, Springer Publishing Company, New York, 205-224.

[41] Wilson, K., Mottram, P.G. and Vassilas, C. (2008) Psychotherapeutic Treatments for Older Depressed People. Cochrane Database of Systematic Reviews, No. 1, Article ID: CD004853.

[42] Hawkley, L.C., Thisted, R.A., Masi, C.M. and Cacioppo, J.T. (2010) Loneliness Predicts Increased Blood Pressure: 5-Year Cross-Lagged Analyses in Middle-Aged and Older Adults. Psychology and Aging, 25, 132-141. http://dx.doi.org/10.1037/a0017805

[43] Liehr, P., Meininger, J.C., Vogler, R., Chan, W., Frazier, L., Smalling, S. and Fuentes, F. (2006) Adding Story-Centered Care to Standard Lifestyle Intervention for People with Stage 1 Hypertension. Applied Nursing Research, 19, 16-21. http://dx.doi.org/10.1016/j.apnr.2004.12.001

[44] Bell, A.C. and D’Zurilla, T.J. (2009) Problem-Solving Therapy for Depression: A Meta-Analysis. Clinical Psychology Review, 29, 348-353. http://dx.doi.org/10.1016/j.cpr.2009.02.003

[45] Sharpe, L., Gittins, C.B., Correia, H.M., Meade, T.W., Nicholas, M.K., Raue, P.J., McDonald, S. and Arean, P.A. (2012) Problem-Solving versus Cognitive Restructuring of Medically Ill Seniors with Depression (PROMISE-D Trial): Study Protocol and Design. BMC Psychiatry, 12, 207. http://dx.doi.org/10.1186/1471-244X-12-207

[46] Maslow, A.H. (2013) Toward a Psychology of Being. Start Publishing LLC, New York.

[47] Mellor, D., Stokes, M., Firth, L., Hayashi, Y. and Cummins, R. (2008) Need for Belonging, Relationship Satisfaction, Loneliness, and Life Satisfaction. Personality and Individual Differences, 45, 213-218. http://dx.doi.org/10.1016/j.paid.2008.03.020

[48] Tomaka, J., Thompson, S. and Palacios, R. (2006) The Relation of Social Isolation, Loneliness, and Social Support to Disease Outcomes among the Elderly. Journal of Aging and Health, 18, 359-384. http://dx.doi.org/10.1177/0898264305280993

[49] Stanley, M., Moyle, W., Ballantyne, A., Jaworski, K., Corlis, M., Oxlade, D., Stoll, A. and Young, B. (2010) Nowadays You Don't Even See Your Neighbours: Loneliness in the Everyday Lives of Older Australians. Health \& Social Care in the Community, 18, 407-414. http://dx.doi.org/10.1111/j.1365-2524.2010.00923.x

[50] Adam, E.K., Chyu, L., Hoyt, L.T., Doane, L.D., Boisjoly, J., Duncan, G.J., Chase-Lansdale, P.L. and McDade, T.W. (2011) Adverse Adolescent Relationship Histories and Young Adult Health: Cumulative Effects of Loneliness, Low Parental Support, Relationship Instability, Intimate Partner Violence, and Loss. Journal of Adolescent Health, 49, 278286. http://dx.doi.org/10.1016/j.jadohealth.2010.12.012

[51] Jones, A.C., Schinka, K.C., van Dulmen, M.H., Bossarte, R.M. and Swahn, M.H. (2011) Changes in Loneliness during Middle Childhood Predict Risk for Adolescent Suicidality Indirectly through Mental Health Problems. Journal of Clinical Child \& Adolescent Psychology, 40, 818-824. http://dx.doi.org/10.1080/15374416.2011.614585

[52] Wei, M.F., Russell, D.W. and Zakalik, R.A. (2005) Adult Attachment, Social Self-Efficacy, Self-Disclosure, Loneliness, and Subsequent Depression for Freshman College Students: A Longitudinal Study. Journal of Counseling Psychology, 52, 602-614. http://dx.doi.org/10.1037/0022-0167.52.4.602

[53] Shankar, A., Hamer, M., McMunn, A. and Steptoe, A. (2013) Social Isolation and Loneliness: Relationships with Cognitive Function during 4 Years of Follow-Up in the English Longitudinal Study of Ageing. Psychosomatic Medicine, 75, 161-170. http://dx.doi.org/10.1097/PSY.0b013e31827f09cd

[54] Hawkley, L.C. and Cacioppo, J.T. (2010) Loneliness Matters: A Theoretical and Empirical Review of Consequences and Mechanisms. Annals of Behavioral Medicine, 40, 218-227. http://dx.doi.org/10.1007/s12160-010-9210-8

[55] Wilson, R.S., Krueger, K.R., Arnold, S.E., Schneider, J.A., Kelly, J.F., Barnes, L.L., Tang, Y. and Bennett, D.A. (2007) Loneliness and Risk of Alzheimer Disease. Archives of General Psychiatry, 64, 234-240.

http://dx.doi.org/10.1001/archpsyc.64.2.234

[56] Buchman, A.S., Boyle, P.A., Wilson, R.S., James, B.D., Leurgans, S.E., Arnold, S.E. and Bennett, D.A. (2010) Loneliness and the Rate of Motor Decline in Old Age: The Rush Memory and Aging Project, a Community-Based Cohort Study. BMC Geriatrics, 10, 77. http://dx.doi.org/10.1186/1471-2318-10-77

[57] Holmen, K., Ericsson, K., Andersson, L. and Winblad, B. (1993) ADL Capacity and Loneliness among Elderly Persons with Cognitive Impairment. Scandinavian Journal of Primary Health Care, 11, 56-60. http://dx.doi.org/10.3109/02813439308994903

[58] Bauminger, N. and Kasari, C. (2000) Loneliness and Friendship in High-Functioning Children with Autism. Child Development, 71, 447-456. http://dx.doi.org/10.1111/1467-8624.00156

[59] Foxall, M.J. and Ekberg, J.Y. (1989) Loneliness of Chronically Ill Adults and Their Spouses. Issues in Mental Health Nursing, 10, 149-167. http://dx.doi.org/10.3109/01612848909140840

[60] Theeke, L.A., Mallow, J.A., Barnes, E., Barr, T.L. and Theeke, E. (2014) The Results of the First Randomized Trial of 
Listen. State of the Science Congress on Nursing Research: Optimizing Health by Addressing Complexity, Washington DC.

[61] Theeke, L.A., Mallow, J.A., Barnes, E. and Barr, T.L. (2014) The Feasibility and Acceptability of the First Listen Trial: A Novel Cognitive Behavioral Therapy for Loneliness. State of the Science Congress on Nursing Research: Optimizing Health by Addressing Complexity, Washington DC.

[62] De Boer, A.G.E., van Lanschot, J.J.B., Stalmeier, P.F.M., van Sandick, J.W., Hulscher, B.F., de Haes, J.C.J. and Sprangers, M.A.G. (2004) Is a Single-Item Visual Analogue Scale as Valid, Reliable and Responsive as Multi-Item Scales in Measuring Quality of Life. Quality of Life Research, 13, 311-320.

[63] Theeke, L., Horstman, P., Mallow, J., Lucke-Wold, N., Culp, S., Domico, J. and Barr, T. (2014) Quality of Life and Loneliness in Stroke Survivors Living in Appalachia. Journal of Neuroscience Nursing, 46, 3-15. http://dx.doi.org/10.1097/JNN.0000000000000097

[64] Theeke, L.A., Newsom, D., Mallow, J.A., Watson, J., Miner, A. and Legg, K. (2013) Loneliness in School Age Children: An Integrative Review of Quantitative Studies. Psychology and Education Journal, 50, 9.

[65] Mallow, J.A., Theeke, L.A., Barnes, E.R. and Mallow, B. (2014) Using mHealth Tools to Improve Rural Diabetes Care Guided by the Chronic Care Model. Online Journal of Rural Nursing and Health Care, 14, 43-65.

[66] Barnes, E., Theeke, L.A., Minchau, E., Mallow, J.A., Wampler, J. and Lucke-Wold, A. (2013) Relationships between Obesity and Depression Management in a University-Based Family Medicine Center. Journal of the American Association of Nurse Practitioners. 
Scientific Research Publishing (SCIRP) is one of the largest Open Access journal publishers. It is currently publishing more than 200 open access, online, peer-reviewed journals covering a wide range of academic disciplines. SCIRP serves the worldwide academic communities and contributes to the progress and application of science with its publication.

Other selected journals from SCIRP are listed as below. Submit your manuscript to us via either submit@scirp.org or Online Submission Portal.
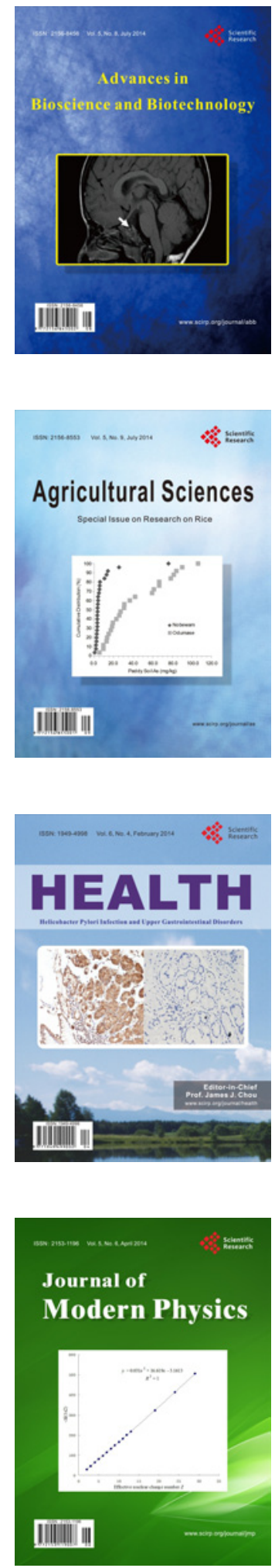
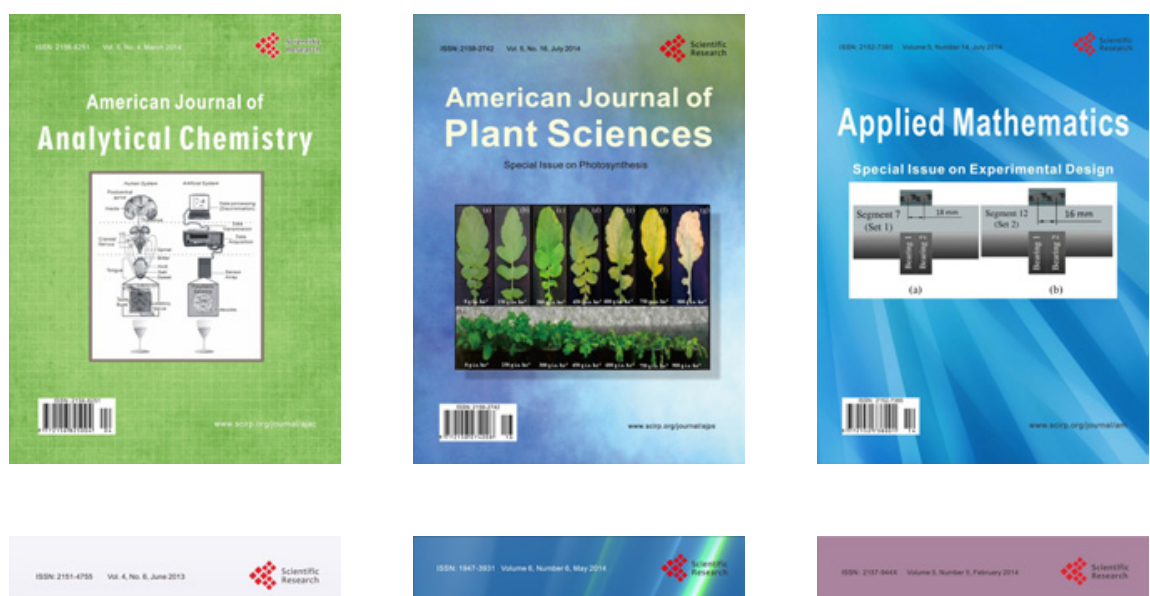

Creative Education
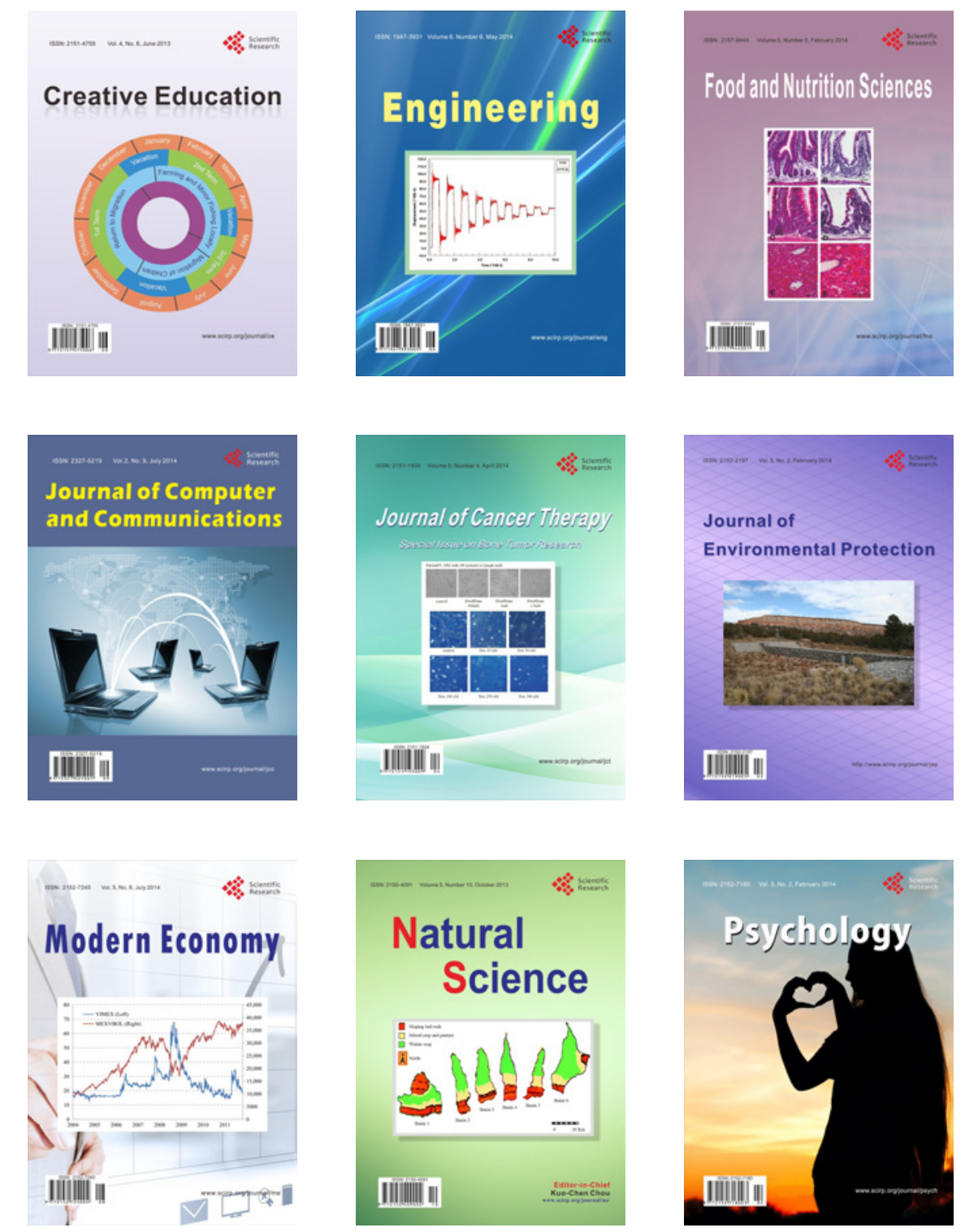